\title{
Introduction to clinical research ethics
}

\author{
Alaa Ismail, $M D$ \\ Department of General Surgery, Ain Shams University
}

\section{Introduction:}

Ethical research principles are considered universal, transcending geographic, cultural, economic, legal and political boundaries. Although these principles are universal, the availability of the resources needed to maintain these principles is not universal. This review will focus on the following headings:

- Principles of Research Ethics

- Foundations of Research Ethics

- Responsible Conduct of Research

- Supervision of Research

\section{Fundamental principles of human research ethics: \\ Fundamental principles of human research ethics are summarized in Table(1).}

\section{Foundation of research ethics:}

The development of research Ethics committees came in response to a history of bad ethical behavior in research studies.

\section{Nuromberg code:}

At the end of World War II, the International Military Tribunal prosecuted Nazi war criminals, including Nazi doctors who performed experiments on concentration-camp prisoners. The tribunal's decision includes what is now called the Nuremberg Code; a 10point statement outlining permissible medical experimentation on human participants.

The first provision of the code requires that "the voluntary informed consent of the human subject is absolutely essential." The code provides other details implied by such a requirement:

-Capacity to consent

-Freedom from coercion

-Comprehension of the risks and benefits involved

Table (1): Fundamental principles of human research ethics.

\begin{tabular}{|l|l|}
\hline Principle & Application \\
\hline $\begin{array}{l}\text { Autonomy - Respect for Persons } \\
\text { Persons with limited autonomy require } \\
\text { special protection }\end{array}$ & $\begin{array}{l}\text { Informed Consent } \\
\text { Confidentiality Protections } \\
\text { Proxy Consent }\end{array}$ \\
\hline Beneficence (nonmaleficence) & $\begin{array}{l}\text { Risk/Benefit Assessment } \\
\text { Minimize Risks by using the best } \\
\text { possible research design }\end{array}$ \\
\hline Justice & $\begin{array}{l}\text { Benefits and risks of research } \\
\text { must be distributed fairly among all } \\
\text { groups }\end{array}$ \\
& $\begin{array}{l}\text { Selection of subjects } \\
\text { avoid selecting groups of individuals } \\
\text { based on easy availability or } \\
\text { compromised position }\end{array}$ \\
\hline
\end{tabular}




\section{Declaration of Helsinki:}

The Declaration of Helsinki was developed by the World Medical Association to remedy perceived voids in the Nuremberg Code, especially as related to physicians conducting research with therapeutic intent with patients. The Helsinki Document was concerned with physicians conducting research on patients and their competing interests between promoting research and protecting human subjects. Accordingly, a major focus of the code was the requirement of independent review of research. Like the Nuremberg Code, the Declaration made informed consent a central requirement for ethical research while allowing for surrogate consent when the research participant is incompetent, physically or mentally incapable of giving consent, or a minor. The Declaration also states that research with these groups should be conducted only when the research is necessary to promote the health of the population represented and when this research cannot be performed on legally competent persons. The document also urged caution if a subject is in a dependent relationship with a physician-research. In that case, the informed consent should be obtained by a well-informed physician who is not engaged in the investigation and who is completely independent of this relationship. The Declaration has been revised five times, most recently in October 2000.

\section{Clinical research after 1960s:}

Did the Nuremberg Code and the Declaration of Helsinki change the conduct of clinical research? The answer is "No", as witnessed by the scandals uncovered in the next paragraph.

\section{Belmont report:}

The Tuskegee Syphilis Study: The most notorious example of research abuse was the Tuskegee research study. This study started out in the 1930s to understand the natural history of untreated syphilis, which at that time involved the use of heavy metals, which were very toxic and it was not known whether the therapy was worse than the natural history of the disease. The study enrolled 400 African Americans with syphilis and 200 uninfected controls. The controversial ethical aspect of this study included failure to adequately explain to the enrolled subjects the nature of the experiment and the procedures, e.g., the subjects were told that lumbar punctures were for therapy. More significantly was the fact that that the U.S. government actively tried to prevent men from receiving penicillin, even when it was known that penicillin was useful for therapy and it was widely available. In 1972, newspaper press reports caused the U.S government to stop the study.

These scandals necessitated the need for establishment of an independent committee to review the research from the ethical point of view and to verify the three golden principles of ethics: autonomy, beneficence, and justice.

Local Regulations \& Guidelines:

While existing International recommendations are important references, they are not a substitute for national or local regulations.

\section{Responsible conduct of research ethics:}

It is essential to begin by answering the basic questions.

\section{What is research?}

Research is a systematic investigation, designed to discover generalizable knowledge.

\section{Who are research participants?}

Research participants are living individuals, about whom a researcher (whether professional or student) obtains data through intervention or interaction with the individual as well as identifiable private information.

What are the pillars of informed consent form?

The informed consent is the consent given to a competent individual who has received the necessary information, has adequately understood the information so that he can make a voluntary decision without having been subjected to coercion, undue influence or inducement, or intimidation.

\section{What are the essential elements for informed consent?}

To write a satisfactory informed consent form, the following items should be included and written in proper patient language: - Description of the research and participant's participation, including identification of 
experimental procedures

- Description of reasonably foreseeable risks

- Description of expected benefits

- Potentially advantageous alternatives to participation

- Explanation of confidentiality

- Explanation of compensation for injuries

- Whom to contact about the research and participants' rights

- Explanation that participation is voluntary

- Documentation of informed consent

Description of the research and participant's participation, including identification of experimental procedures:

There should be a clear, direct statement that the study involves research and is therefore seeking answers to unknown questions. The purpose or objectives of the research must be clearly presented, explaining what new information the study is seeking to obtain. In clinical research, subjects may not be receiving standard or regular health care services.

Participants must agree to be subjected to the procedures required by the study, particularly to those procedures that are experimental. The anticipated duration and the expected participant responsibilities of the study must be clearly stated and agreed upon by participants.

If the study involves randomization and the possible use of a placebo, then participants should understand that they may not be receiving any actual treatment.

\section{Description of reasonably foreseeable risks: Description of expected benefits}

The informed consent must include a description

of any benefits to the subject or to others which may reasonably be expected from the research. The benefits must not be exaggerated and never used to mislead the participant into participating in the research study. Special care is needed in the way benefits

are presented to individuals with limited access to health care services. Offering health care to individuals who would otherwise not have access is a powerful incentive that is potentially coercive.

Finally, information about what benefits or services will be available to participants when the research has ended needs to be described in the informed consent form.

\section{Potentially advantageous alternatives to participation}

The informed consent form must describe treatment alternatives that exist, including other options to participating in the research. Descriptions of alternatives should enable the participant to choose between research procedures or standard procedures.

\section{Explanation of confidentiality}

In the informed consent form, the degree of confidentiality that will be provided should be given. This information should include the names of people or organizations that may review the research records.

Special attention to confidentiality is necessary when public knowledge of participation is potentially damaging. Sometimes the greatest risk to the participant is a breach of confidentiality.

\section{Explanation of compensation for injuries}

Clear information must be provided about any compensation that may be available to the participant if a problem arises during the study. Information must be disclosed about the treatment that would be available and who would pay for it in the case of injury or complications. It is permissible to compensate participants for their time, travel and inconvenience. The amount of this compensation should be reasonable and based on local costs

Compensation should not be so high as to unduly influence a potential participant's decision to participate in the study. Whom to contact about the research and participants' rights?

Information must be provided on whom to contact if a research-related question arises. The contact should not be the researcher or any other person directly related to research. A member of the ethics committee may be an appropriate contact person. The contact information that is provided to the participant should be realistic, economically viable and culturally appropriate.

Explanation that participation is voluntary

In the informed consent form, it is necessary 
to state that participation is absolutely voluntary. This chapter of the informed consent should indicate that refusal to participate in the research or the desire to withdraw from the study will not result in any penalties or loss of benefits to which the participant is otherwise entitled.

\section{Documentation of informed consent}

A consent form itself does not constitute actual informed consent; it is merely documentation. A key component to the process of informed consent is the signing, or documentation, of the consent form by the participant, the researcher and other individuals. All guidelines encourage written documentation when possible. However, a signature does not mean that the participant has understood and given voluntary consent.

\section{How should investigators assess consent?}

This question assesses whether the potential subject actually understands the information they received. Investigators can ask subjects to discuss the information they have received in their own words or give short quizzes. For example, "Can you tell me what the purpose of our study is? What are the risks of the study? How being in our study is different from seeing a regular doctor?" However, researchers have to be aware that such techniques might be evaluating memory rather than comprehension.

Essentially, understanding is processing of disclosed information and is hard to measure. Alternatively, one might want the presence of independent monitors - that is, individuals who can observe the process and decide independently whether the subject understands the information.

\section{Objectives of supervision of research by the review committee: \\ Rationale:}

There is a recognized need for independent review because of the history of research abuse. It has bee recognized that self-regulation by investigators is not sufficient for adequate ethics review. The reason for this is not because scientists are evil or bad, but because they have an interest in promoting research. Consequently, the investigators promote and are enthusiastic about the research, but such enthusiasm might lead them to overestimate the benefits of research and underestimate the risks of research. Their interest in promoting research might come into conflict with the need to protect human subjects. Hence the need for independent review. A second reason for having independent review is to ensure that research adheres to research ethics regulations, which can be quite complex.

\section{Research ethics committee composition:}

Several guidelines have commented on the ideal number of members of the Research Ethics Committee (REC). The basic idea is that Review Committees should not be too small or too big. The idea is to have a certain amount of expertise and representation of different backgrounds. Hence, one needs a certain minimum number. But you don not want it too large, because large numbers of individuals might make discussions of protocols too long. Guidelines have commented on the need to have between 5-12 members.

The requirement to have people with different backgrounds ensures that the REC has people with different expertise to review the many types of research. It is also important to make sure that one has representation from the non-medical and non-science fields for two reasons, first, there is a need to minimize the conflict of interest that scientists might have between the goals of research and that of protecting research subjects. The second is to obtain the input of individuals who represent the community from where the subjects might be recruited. Something for Review Committees to think about is who would be an appropriate representative of the community, i.e., the non-professional community. Is a lawyer adequate, or should it be someone else? Gender balance is another concern. Some Review Committees are regionally based and some are institution-based, and if the latter, where the research is based, it is important to have representation from outside the institution. The key word for all of these requirements is independence from the research project, which could be achieved in many different ways. 


\section{Review committees grades:}

The Review committee may be National, Regional, Institutional, or International belonging to International agencies or organizations

What makes clinical research ethical:

Eight factors have to be satisfied for research to be considered ethical. They are:

1. Community partnership

2. Social value

3. Scientific validity

4. Fair subject selection

5. Favorable risk-benefit ratio

6. Independent review

7. Informed consent

8. Respect for human subjects

These 8 ethical requirements provide a framework for reviewing research and determining whether the research is ethical. Essentially, these eight requirements provide a systematic framework for organizing one's thinking regarding the evaluation of a protocol. Let us consider an actual case to illuminate how the requirements can assess the ethical nature of research.

\section{Community partnership:}

First, to be ethical, clinical research must involve the community in which it occurs. It shouldn't just be done to the community. This requires: a.) community participation in planning, conducting and overseeing research, and integrating research results into the health system; b.) it also involves avoidance of supplanting existing health care services and finally, the sharing rewards with the community; c.) this kind of partnership could have a formal structure, but it could also be done in informal ways. In the US, community leaders petition the Congress concerning priorities for research and there is community representation on research ethics committees. For international research, where there might be foreign sponsors of research, such foreign sponsors must consult with the national Health authorities.

\section{Social values:}

Every research has to have a social value. This means that to be ethical, clinical research must be valuable; it must lead to improvements in health or advancement in generalizable knowledge that is important in the subsequent development of health interventions. Examples of valueless research includes clinical research that has substantial or total overlap with proven results. Such research is called "me-too" studies, i.e., something that you know that it is true and it represents the 5th or 6th study that has studied previous results. Such research only enhances the promotion of someone's career by gaining publication. In the case of international research, the study has to have some value to the health care of the country in which the research is being performed.

Specifically, there are two fundamental reasons why research should have social values. First, valueless research wastes finite social resources. Second, only if society will gain knowledge can one justify exposing human subjects to risk.

\section{Scientific validity:}

The third ethical requirement is scientific validity. Research must be conducted in a methodologically rigorous manner that is practically feasible. Even research asking socially valuable questions can be designed or conducted poorly and produce scientifically unreliable or invalid results.

Invalid research includes underpowered studies, e.g., a randomized study of 18 patients, studies with biased questions, endpoints, instruments, or statistical tests, or studies that cannot enroll sufficient subjects even at the start.

A lot of people might say that assessing the scientific validity of research falls under the responsibility of a scientific review committee and is not the responsibility of an ethics committee. Essentially, the claim is made that there is a distinction between the review of science and ethics. However, studies that are not scientifically sound and will not produce valid results waste resources, waste people's time, and do not justify exposing subjects to burdens or risks. Such research is ethically unsound.

\section{Fair subject selection:}

The selection of subjects must be fair. Subject selection encompasses decisions about who will be enrolled both through the development of specific inclusion and exclusion criteria and the strategy adopted for recruiting subjects. The scientific objectives of the study 
- not vulnerability, privilege, or other factors - should guide decisions about the groups and individuals that will be recruited and enrolled.

In the past, groups such as individuals from an orphanage, mental institution, or prisons sometimes were enrolled because they were convenient or compromised in their ability to protect themselves, even though people from less vulnerable groups could have met the scientific requirements of the study. Also, groups cannot be excluded without scientific reasons. However, higher risk is a reason to exclude certain groups, such as women of child-bearing age in a clinical trial if there is a concern that the drug might present risks to a developing fetus.

Fair subject selection is justified by the principle of distributive justice that entails that both the benefits and burdens generated by social cooperation and activities should be distributed fairly.

\section{Favorable risk-benefit ratio:}

Clinical research inherently entails uncertainty about the degree of risk. Accordingly, for clinical research to be ethical, there must be a favorable risk-benefit ratio. This evaluation involves several steps.

First, one must identify the risks and such risks must be minimized as much as possible by using procedures which are consistent with sound research design. It is important to emphasize that the study design of research might affect risks and hence, members of a research ethics committee must be knowledgeable about study methodology.

Second, potential benefits from the research related activities should be enhanced. In evaluating benefits, one should consider only benefits from the research, not the collateral benefits from added payments or from added health services that individuals might receive from participation. While an individual might consider added health services or payments in his or her consideration of participation, however, a research committee should only consider the benefits that might occur from the research interventions itself when they consider the risk/benefit ratio. If such collateral benefits were considered, then simply by increasing the payment or adding more unrelated services, riskier research would then be allowed.

If the risks are reasonable to potential benefits to the individual, then proceed with the research.

Finally, there is some research that contains procedures that present risks to subjects but without any potential benefits to the individual, for example, many Phase I studies that are just looking at the proper effective dose, or survey studies that might have confidential risks to subjects, without any benefits to subjects. In such cases, one needs to evaluate risks against the social benefit of knowledge gained, or the so-called risk-knowledge ratio.

The requirement for a favorable risk benefit ration is justified by the principles of nonmaleficence and beneficence.

\section{Independent review:}

Investigators have multiple legitimate interests that include promotion of research and the advancement of subject benefit. Frequently, these two interests might be in conflict such that the promotion of research takes precedence over that of subject welfare. Accordingly, such conflict might unwittingly distort the judgment of even well intentioned investigators regarding the design, conduct, and analysis of research. Independent review of the research by members of REC who are unaffiliated with the research helps minimizes these conflicts.

Independent review is also important for another reason. It is a way of guaranteeing society that the benefits will not be achieved from abuse or exploitation of subjects. It maintains public trust in the research.

\section{Respect for human subjects:}

The ethical requirements of research do not end with a signed consent document. Investigators need to show respect for enrolled subjects. Ethics has to go through the whole conduct of the trial, i.e., individuals must continue to be treated with respect throughout the trial.

Respecting enrolled subjects entails at least five different activities.

First, since substantial information will be collected from subjects, their privacy must be protected by ensuring confidentiality of information.

Second, you have to permit people to 
withdraw from the study when they want to withdraw, and you cannot have them jump through hoops to do so and you must allow such withdrawal without penalty.

Third, you need to provide enrolled subjects any new information that has surfaced either from the current study or from other investigations that might affect their continued enrollment in the clinical study.

Fourth, the welfare of subjects should be carefully monitored throughout their participation and investigators have an obligation to take care of them especially if they have some adverse reaction.

Finally, to recognize subjects' contribution to clinical research, there should be some mechanism to inform them of what was learned from the research.

Research ethics is an evolving field. This review only states the principles. Yet, we still have to perform a lot of thinking, awareness campaigns, theoretical and field research, at the national level, before we can say that we have an Egyptian Code of Research Ethics. 